\title{
Implicações da avaliação institucional na gestão universitária: a experiência da Universidade Católica do Salvador (UCSAL)
}

\author{
Maurício da Silva Ferreira \\ Antônio Alberto da Silva Monteiro de Freitas
}

Resumo: A literatura nacional e internacional referente à avaliação das Instituições da Educação Superior (IES) focaliza duas modalidades avaliativas presentes nos sistemas educacionais de diversos países. A primeira modalidade, de caráter externo, dá ênfase à homogeneização e padronização de critérios avaliativos e é centrada na regulação, enquanto que a segunda modalidade, de caráter interno e de matriz educativa e formativa, dá ênfase a diferenciação institucional com suas características e peculiaridades próprias e está centrada na melhoria institucional através de processos de autoavaliação. O objetivo principal deste artigo é enfatizar a segunda modalidade, a partir da pesquisa realizada na Universidade Católica do Salvador, no ano de 2014, como parte integrante do processo de autoavaliação institucional, e analisar em que medida, uma experiência dessa natureza pode, simultaneamente e de forma complementar, ser referencial básico para a regulação e, principalmente, ser um instrumento interno de reestruturação e reorganização institucional. A metodologia adotada foi o estudo de caso, a coexistência de uma abordagem quali-quantitativa e técnica de recolha de dados empíricos decorrente da aplicação de questionários e entrevistas semiestruturadas à comunidade acadêmica. Os principais resultados da pesquisa e o consequente uso desses resultados revelam que a autoavaliação institucional pode se constituir numa forte ferramenta de gestão educacional, através do planejamento participativo, alterando de forma significativa os rumos da instituição e contribuindo de forma decisiva para a melhoria da Universidade e de seus cursos.

Palavras-chave: Avaliação da educação superior. Autoavaliação institucional. Gestão educacional.

\section{Implications of the institutional assessment in the educational administration: the experience of the Universidade Católica do Salvador (UCSAL)}

Abstract: The national and international literature on the evaluation of Higher Education Institutions (HEIs) focuses on two evaluation modalities present in educational systems in different countries. The first modality, of an external nature, emphasizes homogenization and standardization of evaluation criteria and is centered on regulation, while the second modality, with an internal character and an educational and formative model, emphasizes the institutional differentiation with its own characteristics and peculiarities and is focused on institutional improvement through self-assessment processes. The main objective of this paper is to emphasize the second modality, based on the research carried out at the Catholic University of Salvador in 2014, as part of the institutional self-evaluation, and to analyze the extent to which such an experience can be, simultaneously and complementary form, a basic reference for regulation and, above all, be an internal instrument for institutional restructuring and reorganization. The methodology adopted was the case study, the coexistence of a qualitative-quantitative approach and the technique of empirical data collection resulting from the application of questionnaires and semi-structured interviews to the academic community. The main results of the research and the consequent use of these results reveal that institutional self-evaluation may constitute a strong educational management tool, through participatory planning, significantly altering the institution's directions and contributing in a decisive way to the improvement of the University and its courses.

Key words: Higher education assessment. Institutional self-evaluation. Educational administration. 


\section{Introdução}

A avaliação sempre fez parte da vida humana de um modo mais formal ou menos formal e, de um modo geral, está ligada à palavra valoração. Ela é, aliás, por definição, uma atividade de valoração ou de atribuição de valores. Etimologicamente, avaliar, do latim a-valere, pode ser traduzido por "dar a valia a" ou "atribuir valor ou qualidade a".

Apesar de serem variadas e múltiplas as concepções e interpretações sobre o fenômeno avaliativo, há na literatura um consenso de que a avaliação é uma atividade que consiste na obtenção de informações válidas, precisas e fidedignas sobre uma determinada realidade ou atividade, permitindo, assim, sua valoração e posterior tomada de decisão (AFONSO, 2003; LUCKESI, 2010). Ela comporta, portanto, três grandes momentos: o primeiro momento de pesquisa que busca informações de qualidade, o segundo momento de julgamento que leva a uma tomada de decisão e o terceiro momento que se refere ao uso dessa decisão no sentido de melhoria do processo avaliado e que caracteriza o aspecto social da avaliação (TENÓRIO; FERREIRA; LOPES, 2012).

Considerando os elementos que compõem este entendimento inicial de avaliação, segundo os autores citados, pode-se depreender que não se trata de um processo tranquilo, neutro, simples resultado de atividades e conhecimentos meramente técnicos. Antes, é um processo que encontra resistências da comunidade acadêmica na sua implementação, dificuldades de cooperação e participação durante o processo e conflitos de interesses e disputas de poder. Portanto, a avaliação é um fenômeno complexo, contraditório e multirreferencial, nunca linear, cumpre finalidades distintas e atende a interesses diversos.

Esta é a dimensão política e ética da avaliação, referenciada por vários autores. Verificar a que interesse serve e como é que esses interesses são respeitados implica aceitar que a avaliação "é uma atividade que é afetada por forças políticas e que tem efeitos políticos" ou "a avaliação não só deve ser veraz e crível, também deve ser ética e justa” (HOUSE, 1992, p. 52).

Nessa compreensão, a avaliação deve ser um processo socialmente organizado e promovido por atores sociais com legitimidade e competência política, para além da competência técnica, daí porque:

Nenhuma avaliação pode ser realizada num campo vazio de valores e ideologias. Cada uma delas insere-se numa teia de discursos e na produção de sentidos que tenta fazer prevalecer os valores e as marcas 
características dos grupos que a produzem e a sustentam nas distintas situações sociais (DIAS SOBRINHO, 2000, p. 174-175).

Neste contexto, o caráter político da avaliação reflete, necessariamente, a satisfação de determinados interesses e valores de quem avalia e, ao mesmo tempo, requer uma consciência ética, voltada para servir à sociedade, pois a fase de melhoria do processo significa envolvimento e compromisso com a práxis, através da negociação dos conflitos que caracterizam as relações humanas (TENÓRIO; FERREIRA; LOPES, 2012).

No Brasil, é no decorrer dos anos 1980 e 1990, particularmente com o auxílio de levantamentos e estudos realizados por Comissões erigidas pelo Ministério da Educação, que a Avaliação, no contexto das transformações globais, se constituiu como um tema prioritário e passou a fazer parte das agendas nacionais da Educação Superior. Esse interesse deve-se, segundo Dias Sobrinho (2007), não tanto ao seu potencial de transformação qualitativa, de melhoramento pedagógico e de maior eficiência de gestão, mas, principalmente, e com crescente impacto ela se impõe, em função da exigência de regulação e de controle por parte do Estado.

A literatura nacional e internacional focaliza essas duas modalidades de avaliação, uma de caráter interno, de orientação formativa e processual, centrada na melhoria e transformação qualitativa e no papel precípuo da universidade como produtora de cultura e de conhecimento, e outra modalidade que enfatiza a regulação, o controle, a hierarquia, em busca de eficiência e produtividade e o estabelecimento de "rankings" para efeitos comparativos entre as instituições (ROTHEN, 2006; DIAS SOBRINHO, 2008).

Estes dois modelos estão presentes na concepção do Sistema Nacional de Avaliação da Educação Superior (SINAES), implantado no Brasil por meio da Lei 10.861, de 14.04.2004 e com reflexos na Avaliação Institucional, pois pretende assegurar uma coerência tanto conceitual quanto procedimental buscando a articulação de natureza formativa, voltada para a perspectiva de autoconhecimento das instituições, com as funções de natureza regulatória próprias do Estado (RIBEIRO, 2012, p. 307).

Discutir essa complementariedade entre as duas modalidades e os benefícios entre elas não é objetivo deste artigo. A literatura brasileira sobre o tema já é bastante significativa (DIAS SOBRINHO, 2000; VERHINE; MONTEIRO DE FREITAS, 2012).

O objetivo principal deste trabalho é enfatizar a segunda modalidade de avaliação institucional, ou seja, a avaliação de orientação formativa e 
educativa, de caráter endógeno e consequente valorização daquilo que é próprio da Universidade e que constitui sua identidade institucional. Ao mesmo tempo, pretende-se analisar em que medida a avaliação institucional está articulada aos processos de planejamento, organização e gestão da Universidade e em que medida os resultados da avaliação influenciam e definem os rumos institucionais.

Para tanto, a UCSal empreendeu uma pesquisa, pautada nos indicadores do SINAES, durante a etapa de autoavaliação e analisou os resultados na perspectiva da gestão acadêmica e institucional.

A preocupação com o nível de qualidade em que é oferecida a Educação Superior desencadeou vários processos avaliativos de ordem institucional na busca de obter mecanismos que forneçam informações acadêmicas e administrativas para auxiliar na gestão das IES (POLIDORI, 2004).

Nesta compreensão, a avaliação institucional é quase sempre um instrumento fundamental da gestão nas organizações. Particularmente importante na estruturação das relações de trabalho, a avaliação é também um instrumento de controle e de legitimidade organizacional. As instituições educacionais (enquanto organizações complexas) têm utilizado a avaliação para esses mesmos fins (AFONSO, 2000; LIBANEO; FERREIRA; TOCSCHI, 2012).

Acerca da importância da Avaliação Institucional, relacionada com os processos de planejamento e gestão, Dias Sobrinho (2007, p. 15) afirma que "[...] a relação entre avaliação e gestão é de grande importância, pois estabelece aliança entre o conhecimento, a reflexão, a negociação de sentidos e organização e operacionalização de práticas de caráter administrativo e pedagógico". Para que a dimensão de avaliação e gestão se relacione é muito importante que haja uma ampla compreensão da realidade institucional em sua totalidade e de projeção de ações de modo a alcançar os objetivos institucionais. Para Libaneo; Ferreira; Tocschi (2012), isso só é possível graças à ação coordenada e organizada das atividades institucionais em face dos objetivos propostos e isso se dá através do planejamento participativo e da gestão democrática. Isso pressupõe a participação da coletividade no processo de decisões institucionais reforçando o argumento de que:

[...] democracia é um estado de participação. A democracia participativa é aquela em que os cidadãos, ao sentirem-se fazendo parte de um grupo social, têm parte real na sua condução e por isso tomam parte na infindável construção de uma nova sociedade da qual se sentem parte (BORDENAVE, 1994, p. 8). 
Com estas referências, a instituição constrói níveis cada vez mais elevados de participação decisória, rompendo com a tradicional dicotomia entre os que decidem ou planejam e os que executam. Todos os níveis de participação devem estar presentes nos processos democráticos, pois é necessário que todos assumam a plena atuação nas deliberações, das mais simples às mais complexas, exercendo o controle e a avaliação sobre o processo de planejamento e sua execução.

\section{Histórico da avaliação institucional da UCSAL}

A UCSAL é uma instituição de natureza confessional, comunitária e filantrópica, de caráter público não estatal, sem finalidade lucrativa, que aplica seus excedentes financeiros em seu próprio crescimento e melhorias.

Exerce uma função educativa pública e goza de autonomia didático-científica, administrativa, financeira e patrimonial, bem como observa o princípio da indissociabilidade entre ensino, pesquisa e extensão, tendo como Missão:

Formar, pelo amor à busca da verdade, cidadãos éticos e profissionais comprometidos em servir ao ser humano e colaborar com o desenvolvimento social através da excelência no ensino, pesquisa e extensão (UCSAL, 2016, p. 18).

A partir de 2004, atendendo ao artigo $7^{\circ}$ da Portaria MEC no 2051, de 09 de Julho de 2004, que regulamenta os procedimentos de avaliação do SINAES, a UCSAL constituiu a Comissão Própria de Avaliação - CPA com as atribuições de conduzir o processo da avaliação interna da Universidade. Este processo avaliativo, contudo, ainda estava restrito à simples coleta e compilação de dados que subsidiavam a elaboração dos relatórios de autoavaliação institucional, enviados ao MEC a cada ano $^{1}$, e pouco influiu para uma decisiva cultura avaliativa institucional.

A partir de 2014, a CPA passou a exercer um papel fundamental no contexto da nova gestão da Universidade. A necessidade de estabelecer novos padrões qualitativos e críticos das diferentes tarefas institucionais ligadas, sobretudo, às exigências da indissociabilidade entre ensino, pesquisa e extensão, impulsionou a decisão de instituir uma verdadeira e

1 Entre 2004 e 2014 foram enviados 7 (sete) Relatórios de Autoavaliação ao MEC/INEP, a saber: 1) 2004/2006 - Tomos I a V; 2) 2006/2008; 3) 2009; 4) 2010; 5) 2011; 6) 2012; e, 7)2013. Inicialmente de periodicidade bianual, a partir de 2009 , passou a ser anual. 
própria "cultura avaliativa" na Universidade. Para tanto, foi necessária a ampliação-readequação das suas funções e elaboração de um novo Projeto de Avaliação Institucional, articulado aos processos de planejamento e gestão universitária. A vinculação da CPA passou a ser diretamente ligada à Reitoria para maior agilidade na tomada de decisões institucionais, em decorrência dos processos de avaliação, e foi criada uma Comissão Ampliada Cursos/ CPA, integrada por membros do Núcleo Docente Estruturante - NDE de cada curso. A finalidade é a implementação da autoavaliação dos cursos com o alinhamento de uma visão mais aprofundada das demandas de cada curso da UCSAL com vistas a uma maior qualificação dos seus projetos pedagógicos.

\section{Orientações metodológicas}

Esta seção tem como objetivo descrever as opções metodológicas que nortearam o estudo. $\mathrm{Na} 1^{\mathrm{a}}$ etapa é apresentado o contexto de pesquisa e a estratégia geral que foi adotada para o desenvolvimento do trabalho. A $2^{\mathrm{a}}$ etapa refere-se ao universo da pesquisa e aos procedimentos de coleta de dados (questionários e entrevistas semiestruturadas). Na $3^{\text {a }}$ etapa apresenta-se a estratégia de análise e tratamento dos dados com base nas categorias de analise selecionadas e de acordo com o objetivo de investigação.

O objetivo principal deste artigo é enfatizar a avaliação de caráter formativo, a partir de uma pesquisa realizada na Universidade Católica do Salvador, no ano de 2014, como parte integrante do processo de autoavaliação institucional e analisar em que medida uma experiência dessa natureza pode, simultaneamente e de forma complementar, ser referencial básico para a regulação e, principalmente, ser um instrumento interno de reestruturação e reorganização institucional.

\section{Contexto da pesquisa e metodologia adotada}

Esta pesquisa teve como contexto geral a mudança de gestão da Universidade Católica do Salvador - UCSAL que se deu no início de 2014, após um longo período de quase 30 anos de uma mesma Gestão à frente da Instituição. A nova gestão, no início das suas atividades, necessitava de um estudo global e aprofundado sobre a Universidade que lhe desse subsídios para a tomada de decisão em relação a aspectos importantes e estruturantes da Universidade e de seus cursos. 
Iniciou-se, assim, um amplo e detalhado autoconhecimento da Universidade Católica do Salvador, intitulado Escuta UCSAL, com vistas à obtenção de dados e informações relevantes e significativas da Organização. Em face dos resultados e indicativos de linhas de ação propostas por esse documento e após divulgação e ampla reflexão sobre necessidades e prioridades, foram realizadas diversas ações no nível da gestão superior que estão alterando os rumos institucionais.

A metodologia adotada para a construção deste trabalho, nesse contexto de mudanças de gestão, evidencia um compromisso político da nova UCSAL com a abertura de espaços de participação social no seio da comunidade, ao assumir a gestão participativa como eixo estruturante de seu trabalho pedagógico, envolvendo todos os segmentos relacionados à dinâmica pedagógica e administrativa da instituição.

A estratégia geral adotada foi a utilização do estudo de caso e a opção pela coexistência de duas abordagens: quantitativa e qualitativa, envolvendo inicialmente uma parte mais descritiva, e em seguida, um componente mais analítico e explicativo, embora ambas tratadas com a mesma importância e de forma complementar. A pesquisa foi estruturada a partir do aproveitamento dos dados existentes coletados durante a etapa de autoavaliação e decidiu-se por estudá-los sob a ótica da gestão acadêmica e institucional, tendo como referência os parâmetros do SINAES.

É importante ressaltar que para uma melhor oferta dos instrumentos e a coleta dos seus dados, foram utilizados recursos tecnológicos e promovidos encontros nos diversos setores que propiciaram um aprofundamento do conteúdo requerido pelos instrumentos, contribuindo na clarificação das questões demandadas.

\section{Universo da pesquisa}

A metodologia da construção deste trabalho de pesquisa considerou o envolvimento e a participação dos segmentos relacionados com a dinâmica pedagógica e administrativa da Universidade, corpo docente, discente e técnico-administrativo da graduação e da pós-graduação. Responderam à pesquisa 1.873 alunos na graduação (tradicional e tecnológica) e na pós-graduação (lato e stricto sensu), correspondendo a $29,79 \%$ do universo de 9.533 alunos; 102 funcionários técnico-administrativos, correspondendo a $29,22 \%$ do universo de 349 funcionários e todo universo do corpo docente da UCSAL, cerca de 400 professores. 


\title{
Instrumentos de coleta de dados
}

\author{
Questionários
}

Para a constituição da base de dados envolvendo aspectos qualitativos e quantitativos foram aplicados três questionários padronizados para os segmentos alunos, professores e técnico-administrativos, com vinte e oito (28), vinte e quatro (24) e dezenove (19) questões, respectivamente, envolvendo questões gerais relacionadas à infraestrutura, gestão de ensino, pesquisa e extensão e complementadas por uma questão aberta onde os respondentes poderiam comentar ou compartilhar sua opinião sobre algum tema que julgassem relevante vinculado à Universidade e aos cursos ou esclarecer algum ponto que não foi possível ser esclarecido nas questões objetivas onde foi dada a possibilidade de uma única resposta.

Com o objetivo de diversificar os instrumentos de pesquisa e obter maior número de informações de caráter mais qualitativo foram elaborados mais dois questionários com 10 questões objetivas que foram aplicados aos funcionários da Superintendência Acadêmica e das Secretarias de Cursos.

Em junho e dezembro desse mesmo ano, teve início uma segunda coleta de informações com a realização da Pesquisa Discente, quando os estudantes responderam a um questionário online composto por sete variáveis relacionadas a aspectos gerais do curso como: organização didático-pedagógica, corpo docente e infraestrutura.

\section{Entrevistas}

Foram realizadas entrevistas com os professores de Graduação, por curso e optou-se pela técnica de entrevistas semiestruturadas, com um roteiro previamente elaborado, onde os professores responderam a um formulário, explicitando as potencialidades, fragilidades e sugestões de cada curso. Além dessas respostas, por escrito, houve bastante abertura e flexibilidade por parte da equipe coordenadora para que os professores pudessem se colocar livremente.

Estratégia geral de tratamento dos dados

Logo após o período de aplicação dos questionários, começou a ser feita a construção do banco digital a partir da coleta de dados, mediante o emprego de instrumentos específicos de um sistema de informática. O Banco Digital de Dados foi implantado no Núcleo de Informática/UCSAL cujo sistema gerou saída em planilha eletrônica, permitindo a sistematização dos dados 
que foram agrupados de acordo com a escala utilizada nos questionários e foram gerados gráficos, quantificando os principais resultados.

Com relação à parte aberta desses três questionários foi realizada a análise do conteúdo e todos os comentários foram elencados por segmento, numa tabela de respostas com sugestões e de acordo com eixos e dimensões dos SINAES ${ }^{2}$.

Como a natureza das respostas e os segmentos consultados foram bastante diversificados e heterogêneos, procedeu-se a uma analise metodológica diferenciada de cada segmento.

Em relação aos segmentos docente e técnico-administrativo, a partir dos dados coletados pelo Núcleo de Informática, criou-se uma tabela, de acordo com o questionário aplicado e foram distribuídas as respostas com a numeração dos respondentes. Como os respondentes não seguiram a ordem das perguntas formuladas ou não responderam a todas as questões e havendo frequência de conteúdos que não constavam no questionário, manteve-se para cada pergunta a frequência das respostas que foram elencadas em outra coluna e, por último, as respostas foram categorizadas, considerando as dimensões do SINAES.

Do ponto de vista do segmento discente, em relação às questões abertas, após a leitura preliminar do material relativo às respostas mencionadas pelos alunos e em virtude da diversidade de problemas, proposições e sugestões, colocadas numa linguagem de senso-comum, optou-se por se estabelecer, inicialmente, uma pré-codificação dos elementos apresentados. Esta précodificação possibilitou organizar um conjunto de "insumos" constantes nas diversas páginas do material produzido pela fala dos alunos.

$\mathrm{Na}$ sequência, mediante o emprego de planilha eletrônica, estes insumos foram agrupados, também, conforme as dimensões dos SINAES e em seguida, foram gerados gráficos e tabelas correspondentes aos elementos agrupados por essas dimensões e realizada análise específica sobre este material, incorporado aos destaques e indicativos relevantes.

Em relação às entrevistas com o corpo docente, todas as respostas dadas oralmente e por escrito, foram digitadas, organizadas e sistematizadas,

2 Eixo e dimensões do SINAES - Nota Técnica No 14 /2014 - CGACGIES/DAES/INEP/MEC. Eixo 1 - Planejamento e Avaliação Institucional: considera a dimensão 8 (Planejamento e Avaliação). Eixo 2 - Desenvolvimento Institucional: contempla as dimensões 1 (Missão e o Plano de Desenvolvimento Institucional) e 3 (Responsabilidade Social da Instituição). Eixo 3- Políticas Acadêmicas: abrange as dimensões 2 (Políticas para o Ensino, Pesquisa e Extensão), 4 (Comunicação com a Sociedade) e 9 (Políticas de Atendimento aos Discentes). Eixo 4 - Políticas de Gestão: compreende as dimensões 5 (Políticas de Pessoal), 6 (Organização e Gestão da Instituição) e 10 (Sustentabilidade Financeira). Eixo 5 - Infraestrutura Física: contempla a dimensão 7 (Infraestrutura Física). 
seguindo a ordem das entrevistas. Foram consideradas todas as respostas dos entrevistados e organizadas numericamente e em seguida foi extraído o conteúdo das respostas com indicativos de sugestões gerais com base na frequência de respostas.

Na sequência, foi realizada a análise dos dados e das informações resultantes da aplicação dos questionários e entrevistas e foram sugeridos indicativos de linha de ação, gerais e por curso, a serem atendidos, prioritariamente, pela Gestão Superior da Universidade, considerando a preponderância do conteúdo das respostas.

Todo este material serviu de referencial básico para elaboração do Relatório de Autoavaliação Institucional 2015 e para o PDI 2016-2020, elaborado a partir do segundo semestre de 2015, assim como para a revisão do Estatuto da Universidade também realizada neste mesmo período.

\section{Ações gestoras realizadas a partir da avaliação institucional na UCSAL}

A partir das reflexões teóricas aprofundadas na parte introdutória, apresenta-se, nesta seção, a análise dos dados coletados através das pesquisas avaliativas $^{3}$, de acordo com os eixos/dimensões do SINAES e, em seguida, as ações gestoras implementadas pela nova Reitoria da UCSAL, a partir dos resultados da autoavaliação institucional. É importante enfatizar que, apesar das categorias de análise desenvolvidas neste trabalho estarem associadas ao cumprimento de uma exigência legal em função do SINAES, o propósito principal é que essas categorias forneçam subsídios para o aperfeiçoamento da gestão acadêmica e institucional.

É importante destacar que essas dimensões não foram consideradas um instrumento rígido para mera checagem ou verificação de informações. Ao contrário, representaram um ponto de partida para a construção de um amplo processo de reflexão no interior da Instituição com vistas às tomadas de decisões por parte da nova gestão da Universidade.

Eixo 1 - Planejamento e Avaliação Institucional

O Sistema Nacional de Avaliação do Ensino Superior - SINAES - com novas orientações vigentes a partir de 2014, estabeleceu a necessidade de

3 Os dados quantitativos da pesquisa podem ser encontrados no documento Diagnóstico Institucional Consolidado 2014, disponível no site http://www.ucsal.br/institucional/arquivos/diagnostico-institucionalconsolidado.pdf. 
se implementar em todas as IES o Planejamento e Avaliação Institucional como dimensão essencial para se desenvolver, no âmbito dessas instituições, um processo de gestão, organizado e sistemático.

Do ponto de vista operacional, neste artigo, apresenta-se uma breve reflexão sobre a Dimensão 08 - Planejamento e Avaliação, a partir daquilo que disseram os docentes, discentes e técnicos que participaram das pesquisas avaliativas realizadas em 2014 e dos insumos encaminhados pelos Relatórios Específicos dos Cursos de Graduação, das Superintendências, Núcleos e Setores da Universidade, além das observações formuladas sobre o PDI 2011 - 2015 relacionadas ao desenvolvimento da política de atuação para esta área, nestes documentos.

Os resultados das pesquisas e os diferentes relatórios dos cursos de graduação e pós-graduação e demais instâncias da Universidade, refletiram a dificuldade e, até mesmo, a inexistência da utilização de estratégias institucionais relacionadas ao uso constante dos resultados das avaliações, como referência para melhor qualificar as atividades de planejamento, sobretudo na sua dimensão pragmática.

Neste contexto há de se considerar que durante o período 2014/2015 a nova gestão da UCSAL fez um grande esforço para incorporar, gradativamente, um trabalho estratégico voltado para área de planejamento e avaliação, buscando conhecer, organizar, racionalizar e adotar medidas pedagógicas e administrativas capazes de dotar a Instituição de melhoria acadêmica. A criação de Grupos de Trabalho (GT) para estudo e aprofundamento de temáticas importantes da Universidade e proposição de novos projetos a serem implementados; a criação de instrumentos de acompanhamento gerencial de forma a dar suporte à Administração Superior nas tomadas de decisão; a elaboração de planos orçamentários da Universidade e dos cursos de forma a se elegerem os temas prioritários que devem compor o escopo do planejamento em curto prazo, são algumas das ações implementadas pela nova Reitoria no período 2014-2015.

A dimensão Planejamento e Avaliação vem sendo, portanto, incorporada à dinâmica institucional na atualidade e para garantir eficiência a todo esse processo foi proposta a criação de uma Assessoria de Planejamento e Avaliação, vinculada à Reitoria, que passa a fazer parte do novo desenho organizacional da UCSAL, no contexto da reestruturação do novo Estatuto da Universidade, cuja organização e funcionamento encontram-se delineados através de atividades necessárias à melhoria acadêmica da Instituição. 
Esta Assessoria constitui o embrião orientador na construção de um processo de planejamento e avaliação compatível com as necessidades mais emergentes da Instituição, a qual deverá manter uma articulação sistemática e permanente com a Comissão Própria de Avaliação - CPA/ UCSAL.

Estes esforços, porém, não estão circunscritos ao horizonte hierárquico gerencial. Não se trata de uma ordem "de cima", mas de contribuir para que os esforços resultem numa cultura avaliativa institucional que anime as estratégias, o planejamento e a própria avaliação institucional.

\section{Eixo 2 - Desenvolvimento Institucional}

O processo de Desenvolvimento Institucional consiste na possibilidade objetiva da Universidade viabilizar o ensino, a pesquisa, a extensão e a gestão, mediante a realização de projetos, atividades e prestação de serviços essenciais, conforme a perspectiva prevista na sua missão institucional.

Para isso, do ponto de vista operacional a UCSAL, tendo como referencia o seu PDI (2011-2015), elegeu três grandes metas ${ }^{4}$ para este período, relacionadas ao cumprimento e divulgação da sua missão e da execução de ações vinculadas à área da responsabilidade social.

Em relação à disseminação de ações correspondentes à missão institucional prevista no PDI (2011-2015), identifica-se que na maioria dos documentos institucionais, o seu conteúdo está explicitado, embora haja por parte da comunidade acadêmica, docentes, discentes e técnicos, algumas observações quanto à necessidade dos documentos institucionais serem apresentados de maneira mais didática, objetivando estimular e ampliar a leitura pelos docentes, discentes, colaboradores e do público em geral.

No período 2014/2015 algumas ações pedagógicas foram efetivadas pela UCSAL, numa perspectiva de se recolocar para a comunidade acadêmica a necessidade do fortalecimento da sua Missão Institucional. Para isso, foram realizados encontros, seminários e trabalho de assessoramento às Coordenações em Geral e NDE dos cursos, tendo como referência uma reflexão crítica da sua missão institucional, objetivando a elaboração do novo PDI, PPI e reformulação das matrizes curriculares dos PPC.

Outro aspecto significativo relacionado à dimensão Responsabilidade Social refere-se à implementação do Programa Católica Social, lançado

4 Para a dimensão Missão e PDI foram estabelecidas duas metas, a saber: divulgar permanentemente a Missão Institucional em toda a comunidade acadêmica; e, acompanhar continuamente a execução das metas e ações propostas neste PDI. Para a dimensão Responsabilidade Social a meta definida foi assegurar a continuidade dos 8 projetos de extensão e de ação comunitária. 
no ano de 2014, cujo conteúdo responde a uma vocação institucional de inclusão social da Universidade, possibilitando a incorporação de número significativo de alunos em seus cursos de graduação.

Diversas ações, nessa direção, foram realizadas, a exemplo de parceria da Universidade Católica com a Rede Municipal de Educação através do Projeto Agentes da Educação, envolvendo os cursos de Pedagogia e Serviço Social, com o objetivo de melhorar o desempenho escolar dos estudantes da escola pública municipal mediante o fortalecimento de vínculos entre família, escola e comunidade. Foi realizado também um acordo de cooperação com o Sistema Federação das Indústrias do Estado da Bahia - FIEB, com o objetivo de obter apoio para o desenvolvimento do Projeto de Educação Empreendedora, onde os alunos da UCSAL têm a possibilidade de vivenciarem a integração entre o conhecimento e a prática e exercer atividades relacionadas à área de seu curso em projetos e programas desenvolvidos pelo Sistema FIEB.

Outras ações ainda foram implementadas neste contexto: estímulo aos servidores técnico-administrativos para realização de cursos de graduação na Instituição, no sentido de melhoria da sua qualificação profissional; participação de membros do NDE nos Núcleos de Extensão; atividades relacionadas aos direitos sociais, incorporando Seminário sobre Redução da Maioridade Penal e suas implicações, dentre outras.

Dessa forma, percebe-se através do conjunto das atividades desenvolvidas, o cumprimento da sua missão institucional e o fortalecimento da Responsabilidade Social como dimensões essenciais para o funcionamento da UCSAL, enfatizando o cumprimento da sua natureza confessional, comunitária e filantrópica.

\section{Eixo 3 - Políticas Acadêmicas}

O desenvolvimento das Políticas Acadêmicas integrantes do Eixo 03 constitui a centralidade do conjunto das ações, projetos e atividades realizadas no âmbito da UCSAL no que se refere às políticas de ensino, pesquisa e extensão, comunicação com a sociedade e políticas de atendimento aos discentes.

Os resultados das pesquisas avaliativas, a partir daquilo que disseram os docentes, discentes e técnicos, possibilitaram conhecer melhor a dinâmica institucional nessas dimensões e refletiram algumas dificuldades relacionadas ao pouco estímulo, dado pela UCSAL, à Pesquisa Docente, assim 
como às ações extensionistas; à ausência de uma política clara de apoio e atendimento aos discentes e à comunicação da UCSAL, tanto na relação interna quanto com a sociedade em geral.

Aspectos relacionados às avaliações externas dos cursos da UCSAL também foram mencionados, considerando que houve ainda muitos cursos que receberam conceito inferior a 3 (nota 1 e $2-C P C$; ENADE e, às vezes, em ambos), demandando novas visitas da Comissão de Especialistas do MEC para Reconhecimento ou Renovação de Reconhecimento dos Cursos.

O conjunto dessas informações levou a um novo redirecionamento da Universidade, adotando uma política acadêmica que prioriza uma maior atenção aos cursos de graduação e pós-graduação, enfatizando a titulação docente, tempo dedicado à Instituição, produção acadêmica, infraestrutura dos laboratórios assim como a qualidade de atendimento aos discentes, objetivando melhores resultados nas próximas avaliações externas.

Nesse contexto, a nova gestão da Universidade, buscando recuperar a melhoria das condições dos cursos de graduação, teve quatro cursos avaliados pelo MEC em 2014 com nota 4 (quatro) $^{5}$ no conceito final. Na Pós-Graduação Stricto Sensu, a UCSAL também se destacou com a aprovação pela CAPES do Doutorado de Políticas Sociais e Cidadania em 2014, além de um conjunto de programas de mestrado e doutorado avaliados com nível de excelência pela CAPES ${ }^{6}$.

Do ponto de vista institucional, o conteúdo dos Relatórios Setoriais dos gestores acadêmicos e administrativos ${ }^{7}$ apresenta uma diversidade de ações empreendidas pelo ensino, pesquisa e extensão, as quais buscam dinamizar e qualificar os serviços educacionais prestados pela Universidade.

Neste contexto se insere o estudo aprofundado das condições de existência e sustentabilidade acadêmica, laboratorial e financeira dos Cursos oferecidos pela Graduação e Pós-Graduação. Estudo que rendeu instrumentos aptos a decisões estratégicas de reavaliação, reordenamento e estruturação para a contratação de novos professores, técnicos e equipamentos, resultando na melhoria acadêmica e técnica dos Cursos, aumento de alunos matriculados e planejamento de iniciativas e ações de pesquisa e extensão ligadas ao ensino.

5 Os cursos com conceito final 4 foram: CST em Análise e Desenvolvimento de Sistemas para Reconhecimento; Secretariado Executivo - Bacharelado, Letras - Língua Portuguesa e Teologia para Renovação de Reconhecimento de Curso; CST em Marketing para Autorização.

6 Os programas de Mestrado e Doutorado Família na Sociedade Contemporânea obtiveram nota 5, e os programas de Mestrado e Doutorado de Planejamento Territorial e Desenvolvimento Local, nota 4.

7 Esse conteúdo pode ser encontrado no Relatório de Autoavaliação Institucional 2014. Disponível em: http://www.ucsal.br/articles/0002/6854/Relat_rio_de_Autoavalia_o_Institucional_2014.pdf. 
O conjunto dessas ações e estratégias empreendidas pela Universidade a partir de 2014, aliado aos objetivos estabelecidos para o novo PDI 20162020 indicam novos rumos e orientações que estão sendo percorridos pela Instituição, objetivando modernizá-la e adequá-la aos atuais desafios do mundo do trabalho e da sociedade brasileira.

\section{Eixo 4 - Políticas de Gestão}

O processo de construção das Políticas de Gestão deve considerar inicialmente o funcionamento institucional, a dinâmica organizacional, suas peculiaridades, sua trajetória, ordenamento e sistema decisório.

Durante o período 2014/2015, a nova gestão da UCSAL, com o apoio da Avaliação Institucional, buscou conhecer de modo mais específico a estrutura de pessoal existente no âmbito do Corpo Docente e Técnico Administrativo, seus processos de trabalho, procedimentos e rotinas, tendo em vista o estabelecimento de um diagnóstico sobre a área, objetivando empreender a reorganização do Setor de Gestão de Pessoas/RH e todas as alterações necessárias ao atual momento da Universidade.

Do ponto de vista pragmático, o diagnóstico resultante do processo das pesquisas realizadas, a partir daquilo que disseram os docentes, discentes e técnicos, identificou fragilidades relacionadas à titulação e capacitação docente, qualificação técnico-administrativa, número reduzido de cursos com coordenação especifica da área, dispersão de cursos em vários campi simultaneamente, cursos com baixa sustentabilidade financeira, desarticulação na utilização dos recursos/contratos, diferença nos salários de funcionários desempenhando a mesma função, inexistência de programas de seleção para professores e técnicos, dentre outros.

Este conjunto de aspectos acima mencionados requereu da Universidade a adoção de alguns mecanismos e estratégias de trabalho, no sentido de minimizar a diversidade de situações de natureza pedagógica-administrativas, a serem gradativamente equacionadas.

Para isso, como medida de gestão, a Universidade implementou as seguintes ações: estabelecimento de Coordenações por curso com os seus respectivos Núcleos Docentes Estruturantes - NDE e Colegiados por Curso; realização de estudo e desenvolvimento de ações para captação de novos alunos; elaboração do diagnóstico da área de extensão e seu redimensionamento; implantação dos Núcleos de Assistência à Coordenação - NAC; oferta de novos cursos de graduação e pós-graduação lato e stricto sensu; 
ações para melhoria da integração entre professores de diferentes cursos; oferta de curso de formação continuada para professores; reestruturação do Plano de Classificação de Cargos e Salários (PCCS) com incorporação de novos professores ao regime de tempo parcial e integral; capacitação para funcionários e professores, tendo em vista implantar novos procedimentos tecnológicos; especialização em Docência Universitária para professores que precisam de qualificação conforme requisitos da L.D.B; estímulo a professores para ingresso na carreira docente e adoção de novos procedimentos pedagógico-administrativos.

A implementação dessas ações tem proporcionado à Universidade a Institucionalização de um novo ordenamento acadêmico, estratégico, administrativo financeiro e de marketing, objetivando torná-la adequada e capacitada para o enfrentamento dos novos desafios presentes no cenário da Educação Superior Brasileira.

\section{Eixo 5 - Infraestrutura Física}

Conforme a finalidade prevista na Dimensão 7: Infraestrutura Física e Tecnológica, sua característica essencial deve ser o de assegurar o desenvolvimento das atividades meio da Universidade em consonância com a sua missão Institucional.

Visando equacionar um conjunto de situações que indicavam fragilida$\operatorname{des}^{8}$ da instituição nesta área, a partir daquilo que disseram os docentes, discentes e técnicos, foram implementadas diversas atividades no âmbito da Universidade, no sentido do fortalecimento do apoio logístico para subsidiar a área acadêmica. Esta estratégia de trabalho faz parte da nova reorganização Institucional necessária à UCSAL, no sentido de torná-la mais ágil e ao mesmo tempo mais eficiente com implementação de procedimentos, rotinas e fluxos de trabalho compatíveis com as necessidades do corpo docente, discente, funcionários e público em geral, que buscam utilizar, com satisfação, os serviços educacionais prestados pela UCSAL.

Foram implementados os seguintes serviços e procedimentos: implantação da Secretaria Geral de Cursos - SGC; modernização das instalações físicas da biblioteca; ampliação da capacidade de armazenamento do acervo

8 As principais fragilidades foram: acesso à Internet na UCSal, considerando que houve um percentual alto de respostas regular e fraco (47\%); melhoria dos LAMI, considerando que uma boa parte dos estudantes atribuiu conceito regular a esta área $(27,28 \%)$ e fraco $(19,40 \%)$. Merece especial atenção o percentual alto de respostas entre regular e fraco (58\%) no que se refere aos equipamentos da sala de aula e em relação ao acervo das bibliotecas, considerando também o alto percentual de respostas entre regular e fraco (35\%). 
bibliográfico; reforma dos espaços para implantação dos Núcleos de Assistência à Coordenação - NAC; reforma dos Laboratórios nos Campus; climatização das salas; adoção de novos sistemas para gestão administrativa e acadêmica (Sistema Aberto de Gestão Unificada - SAGU, Caderneta Eletrônica, Portal do Professor, UCSAL Mobile); criação de canal direto de comunicação para aprimoramento dos serviços prestados pela Universidade; reformulação do ambiente virtual do Sistema de Bibliotecas; implantação de estruturas e contratação de profissionais aptos ao início das atividades do Ensino a Distância (EAD); reorganização de novos espaços de trabalho para adequação do funcionamento das atividades administrativas; estruturação do sistema de segurança eletrônica com aquisição de equipamentos modernos de vigilância eletrônica e levantamento arquitetônico para a nova sede da Reitoria.

Esse processo de trabalho realizado no período 2014/2015 permitiu o fortalecimento de ações para reorganização da área de tecnologia no âmbito da UCSAL; inserção de novos procedimentos administrativos; redimensionamento dos fluxos de informação; melhoria da acessibilidade nos Campi; dinamização do atendimento aos discentes; utilização de novos espaços de integração entre os professores de cursos; implementação do Campus Virtual para melhorar interação entre a comunidade acadêmica; aprimoramento de procedimentos financeiros mediante novas ferramentas eletrônicas, dentre outros.

Este conjunto de estratégias e ações projetadas a partir dos processos avaliativos tem contribuído para que a área tecnológica e administrativa possa cumprir o seu papel precípuo de possibilitar o desenvolvimento, na Universidade, das atividades ligadas ao ensino, pesquisa e extensão.

Implicações da avaliação institucional no âmbito da gestão universitária período 2014-2015

$\mathrm{Na}$ atualidade, habilitar o processo de gestão universitária constitui-se numa demanda fundamental para qualificação da melhoria da prestação dos serviços educacionais e o redesenho de novos processos de trabalho, inovação e tecnologia de gestão, no âmbito das IES.

Desse modo, em todas as instâncias da UCSAL percebe-se o impacto da avaliação no cotidiano da Universidade no período 2014/2015, em diferentes ações gestoras, sejam elas de âmbito restrito de um setor ou de impacto amplo na comunidade acadêmica. Fica evidente que os resultados 
da avaliação institucional e a análise e discussão desses resultados, assim como o estímulo constante às mudanças por parte da Reitoria, foram aspectos imprescindíveis para que a avaliação se consolidasse como ferramenta de gestão e melhoramento pedagógico.

Nesse contexto, a Universidade desenvolveu uma nova estratégia de trabalho em diferentes momentos, cujas medidas adotadas possibilitaram o estabelecimento de princípios de gestão essenciais como participação da comunidade acadêmica, tendo como base o exercício do diálogo; articulação Universidade/comunidade; eficiência dos processos acadêmico-administrativos subsidiados pela adoção de rotinas, procedimentos e utilização de instrumentos compatíveis com a ética e a legislação educacional vigente, garantindo os fins últimos do papel da Universidade de promover um ensino de excelência, através da produção e disseminação do conhecimento científico.

Este movimento gerou um esforço reflexivo-crítico no seio da comunidade acadêmica, conduzindo a uma ação consciente e organizada não apenas para conhecer de forma aprofundada a realidade institucional, mas também explicitar potencialidades e buscar objetivamente assumir as responsabilidades coletivas para o crescimento e desenvolvimento da Universidade.

Deste modo, as respostas dadas pela Instituição no período 2014/2015, como imperativo dos processos avaliativos, resultaram na combinação de um conjunto de ações articuladas e simultâneas no âmbito do ensino, pesquisa e extensão, subsidiada por atividades, procedimentos, serviços de atendimento, tecnologia e medidas administrativas que contribuíram enormemente para a melhoria do processo de desenvolvimento acadêmico, administrativo e de gestão estratégica da Universidade.

Para isso, os primeiros resultados da avaliação institucional constantes nos relatórios de autoavaliação 2014 e 2015, refletem um novo olhar sobre a gestão universitária adotada pela UCSAL, qualificando a Instituição para o momento atual, tendo como horizonte a elaboração e o desenvolvimento de seu Plano de Desenvolvimento Institucional (PDI) - 2016-20209.

A avaliação associada à tomada de decisão, neste artigo sendo compreendida como uma dimensão da gestão, representou uma forte vontade política e uma confiança muito grande da comunidade acadêmica nos efeitos positivos desse processo, para que a UCSAL começasse a vislumbrar um

9 De acordo com a Comissão Interna (2014) que apresentou proposta para elaboração do PDI, os objetivos principais desse documento são: projetar o caminho futuro da UCSAL por um período de cinco anos; criar a cultura de planejamento institucional, articulado à avaliação; e, traçar objetivos, metas e ações que a Universidade deve assumir nas áreas de ensino, pesquisa e extensão, no período estabelecido. 
novo momento histórico em sua trajetória de Universidade superando o período de quase 30 anos sob um mesmo modelo de gestão com seus sinais claros de esgotamento.

\section{Considerações Finais}

A avaliação institucional da UCSAL representou uma força motriz de ações inovadoras e de mudanças positivas que ocorreram no período 2014/2015, tendo implicações diretas no novo modelo de gestão da UCSAL, com alterações significativas nos rumos institucionais. Com a realização da autoavaliação institucional, o processo de tomada de decisão pôde ocorrer de maneira segura, transparente e com a participação de todos os segmentos da comunidade acadêmica.

Neste novo momento da UCSAL, de revisão do seu Estatuto e do seu novo PDI, a avaliação institucional lança novos desafios à Universidade, com indicativos de grandes linhas de ação e grandes objetivos que devem fazer parte do horizonte da gestão da UCSAL para os próximos cinco anos.

Neste ato de trilhar o caminho da excelência e da qualidade do processo educativo, destaca-se, de um lado, a importância de refletir sobre as relações mais amplas da Universidade com implantação de políticas institucionais alicerçadas na visão estratégica; de outro, a busca de ressignificar os pressupostos teórico-metodológicos que devem embasar a construção do novo PDI.

Embora muitos dos objetivos propostos para o PDI 2016-2020 já começaram a ser desenvolvidos no período 2014/2015, eles ainda devem ser considerados nos próximos anos por representarem desafios e eixos estruturantes para o futuro da UCSAL que pretende se transformar em PUC/Bahia por solicitação da comunidade acadêmica. Esses objetivos estão relacionados à sustentabilidade e perenidade da instituição; ao fortalecimento da imagem e construção da sua marca; à ampliação da captação e fidelização dos alunos; à eficiência e efetividade dos processos acadêmicos, técnico-administrativos e de comunicação; à excelência e desempenho do corpo funcional assim como à ampliação das ações extensionistas e produção científica institucionalizada.

A análise e discussão destes objetivos, pela Comunidade Acadêmica, assim como a trajetória de sua implementação, associada ao processo formativo e desenvolvimento dos quadros da UCSAL, no contexto de elaboração do novo PDI, revela uma grande riqueza de possibilidades de exploração que podem abrir caminhos e perspectivas para trabalhos futuros. 


\section{Referências}

AFONSO, Almerindo Janela. Avaliação educacional: regulação e emancipação. São Paulo: Cortez, 2000.

AFONSO, Almerindo Janela. Estado, globalização e políticas educacionais: elementos para uma agenda de investigação. Revista Brasileira de Educação, Rio de Janeiro, n. 22, jan./fev./mar./ abr. 2003.

BORDENAVE, Juan E. Diaz. O que é participação. 8. ed. São Paulo: Brasiliense, 1994.

DIAS SOBRINHO, José. Avaliação da educação superior. Petrópolis: Vozes, 2000.

DIAS SOBRINHO, José. Prefácio. In: MARBACK NETO, Guilherme. Avaliação: instrumento de gestão universitária. Vila Velha, ES: Hoper, 2007. p. 11-16.

DIAS SOBRINHO, José. Qualidade, avaliação: do Sinaes a índices. Avaliação: Revista de Avaliação da Educação Superior, Campinas; Sorocaba, v. 13. n. 03, 2008.

HOUSE, Ernest R. Tendencias en evaluación. Revista de Educación, Madri, n. 299, 1992.

LIBANEO, José Carlos; FERREIRA, João Ferreira; TOCSCHI, Mirza Seabra. Educação Escolar: políticas, estrutura e organização. 10. ed. São Paulo: Cortez, 2012.

LUCKESI, Cipriano Carlos. Avaliação da aprendizagem escolar: estudos e proposições. 22. ed. São Paulo: Cortez, 2010.

POLIDORI, Marlis Morosini. Construindo políticas educacionais com o suporte da avaliação da educação superior. In: CONGRESSO LUSO-AFROBRASILEIRO DE CIÊNCIAS SOCIAIS, 8., 2004. Anais... Coimbra, 2004.

RIBEIRO, Elisa Antonia. As atuais políticas públicas de avaliação para a educação superior e os impactos na configuração do trabalho docente. Avaliação, Campinas; Sorocaba, v. 17, n. 02, 2012. 
ROTHEN, José Carlos. Ponto e contraponto na avaliação institucional: análise dos documentos de implantação do SINAES. Revista Educação, Belo Horizonte, v. 15. n. 27, p. 119-137, 2006.

TENÓRIO, Robinson Moreira; FERREIRA, Rosilda Arruda Ferreira; LOPES, Uaçaí de Magalhães. Avaliação e resiliência: diagnosticar, negociar e melhorar. Salvador: EDUFBA, 2012.

VERHINE, Robert E.; MONTEIRO DE FREITAS, Antônio Alberto da Silva. A avaliação da educação superior: modalidades e tendências no cenário internacional. Campinas: Ed. UNICAMP, 2012.

UCSAL. Plano de Desenvolvimento Institucional -PDI - 2011-2015.

UCSAL, 2011. Disponível em: <http://www.ucsal.br/institucional/arquivos/ pdi-ucsal-2011-2015.pdf>. Acesso em: 02 abr. 2015.

UCSAL. Plano de Desenvolvimento Institucional -PDI - 2016-2020.

UCSAL, 2016. Disponível em: <http://www.ucsal.br/institucional/arquivos/ pdi-ucsal-2016-2020.pdf>. Acesso em: 01 mar. 2016.

Maurício da Silva Ferreira - Universidade Católica do Salvador Salvador | BA | Brasil. Contato: paramauricio@gmail.com

Antônio Alberto da Silva Monteiro de Freitas Universidade Católica do Salvador | Salvador | BA | Brasil. Contato: a.albertofreitas@hotmail.com

Artigo recebido em 21 de agosto de 2015 e aprovado em 19 de abril de 2016. 
